also right in supposing that bronchodilator aerosols can become less effective if excessively used. They do not, however, explain exactly how the resultant worsening asthma caused the special kind of sudden and unexpected deaths which mainly contributed to the reported rise in death rate.

In our view, a more likely cause of the unexpected deaths is massive overdosage with isoprenaline by hypoxic individuals, because the victims were often found with empty inhalers. This explanation is incompatible with the Conolly group's hypothesis if only because it is hard to see why any patient should die after an overdose of a substance to which he is tolerant. It also conflicts with their claim that inhaled isoprenaline is not well enough absorbed to cause serious systemic effects. This is certainly untrue for dogs. We found ${ }^{2}{ }^{3}$ that overdosage with an aerosol containing isoprenaline and Arctons 11 and 12 as propellents caused deaths in conscious dogs if they were deprived of air during the dosing procedure; no deaths occurred after similar treatment with aerosols containing only propellents, or propellents and salbutamol. Large doses of isoprenaline by aerosol are, therefore, potentially lethal to hypoxic dogs. The same may well be true for hypoxic human beings because human beings and dogs are usually alike in their cardiovascular responses.

This explanation is consistent with all the facts known to us concerning unexpected deaths associated with aerosol bronchodilators. If it is essentially correct it would be a pity if, as a result of the warning in your leading article, patients resumed the use of isoprenaline-containing aerosols instead of those containing drugs such as salbutamol which are likely to be safer even if they are abused.-We are, etc.,

David Jack R:search Director

DAVID HARRIS

Head of Medical Services, Research Division Ware, Herts Allen and Hanburys Ltd

1 Conolly, M. E.. Davies, D. S.. Dollery, C.T., and George, C. F.. British fournal of Pharma-

cology, 1971, 43, 389.
Poynter, D., and Snurlino, N. W. Postoraduate Medical Fourna', 1971, 47, Suppl. (M-rch) 21.
Jack, D.. British Medical fournal, 1971, 2, 708.

SIR,-I was most interested to read your leading article "Resistance to $\beta$-Adrenoceptor Stimulants" (15 January, p. 127). I have pointed out ( 30 March, 1968, p. 837) that overusage of isoprenaline not only results in failure to induce the desired bronchodilator effect but also may bring about bronchoconstriction.

Conolly et al. ${ }^{1}$ have suggested that the rise in deaths from asthma could have resulted from lowering of the sympathetic drive on which asthmatics greatly rely to maintain bronchodilatation. This seems a most reasonable explanation, but I suggest that it is only part of the mechanism. In my work on the uterus ${ }^{2} I$ have induced resistance to isoprenaline and I have found that in this situation resistance to all catecholamines occurs and the response of the tissue reverses, becoming motor instead of inhibitory. Induction of resistance coincides with the liheration of prostaglandin ${ }^{3}$ and furthermore I have found that resistance to catecholamines can be induced by first subjecting the tissue to prostaglandin.
The response of the tissue to prostaglandin is motor.

Thus in the instance where the asthmatic has so overused isoprenaline as to induce a state of resistance he has not only lowered the effectiveness of his sympathetic drive but also he may be releasing prostaglandin and possibly inducing bronchoconstriction. This in itself would be quite sufficient to account for the reported rise in deaths from asthma.

Since the use of isoprenaline sprays is largely in the hands of unsupervised patients would it not be worth forestalling the synthesis of prostaglandin with concomitant use of analgesic agents ${ }^{4}$ or their release by the use of certain psychotropic drugs? ${ }^{5}$ -I am, etc.

ANNE TOTHILL

London N.W.8

1 Conolly, M. E., Davies, D. S., Dollery, C. T., and George, C. F. Fritish fournal of Pharma-

cology, 1971, 43, 389 . Foumal of Pharmacology, $1967,29,291$

Tothill, Anne, Rathbone, L., and Willman, Eve, Nature, $1971,233,56$.

Vane, J. R., Nature, New Biology, 1971, 231, 232. Lan zet, 1971, 2, 381 .

\section{Carcinoma of the Vulva}

SIR,-I have read Mr. A. H. Charles's article "Carcinoma of the Vulva" (12 February, p. 397) with great interest. As one who formerly practised the Way radical vulvectomy but who now tends to a more conservative approach, I should like to add a few comments, particularly on the aspect of wound closure. While the delayed rotation flap principle is most commendable in itself, I would point out that, in the particular circumstances of the radical vulvectomy operation, conventional skin grafting still has much to offer. An open vulvectomy wound becomes covered with reasonably healthy granulations two to three weeks after the primary operation; if split skin grafts of intermediate thickness taken from the thigh are managed by the open method, an $80-90 \%$ take results. The patient can be discharged after a relatively short period of hospitalization, without contractures or similar disability in the grafted area.

The choice of skin cover is further influenced by the extent of the primary operation. Few would deny that in the vulva proper wide ablation is mandatory; apart from removal of at least $4 \mathrm{~cm}$ of tissue from the area around the primary growth, which may be multicentric, the whole leukoplakic or potentially leukoplakic skin area must be sacrificed. The dissection must be carried laterally to the inguino-crural folds. It is probable, indeed, that the poor results from the older literature of the conventional simple vulvectomy operation are largely attributable to neglect of this principle. As regards the skin over the groin and Scarpa's triangle, however, it is questionable whether the somewhat liberal skin sacrifice of the Way operation is justified; too pessimistic a view has been taken of the results of primary wound closure there, and primary closure means a smaller vulvectomy wound without the attendant problems of saline and plasma replacement.

A related problem is the role of excision of the inguinal glands, where these are clinically uninvolved. This is but one example of an issue currently much debated in the whole field of cancer surgery. For the older patient an "extended simple vulvectomy," as above, without gland dissection but supplemented with cancer chemotherapy is, in my experience, adequate. I give chemotherapy routinely. Secondary open grafting will then generally also be required. Where, in other cases, block dissection of the inguinal glands is added, a choice has to be made between secondary grafting and the delayed flap rotation method. As already mentioned, I find no practical advantage as regards texture in full thickness skin cover for the vulva. Again, the risk to grafted skin of recurrent leukoplakia, with its due cancer potential, is offset by the hazard of cancer cell mobilization during the manipulations inherent in flap fashioning in a malignant field prior to definitive surgery. Indeed, from the practical standpoint recurrent leukoplakia is seldom a problem in the woman who has had vulvectomy for cancer.

Hence it is submitted that there is a place, particularly in old patients. for the relatively simple method of open grafting, combined where necessary with primary groin wound suture.

Congleton, Cheshire

A. W. BANKS

\section{Vaccination against Rubella}

SIR,-Drs. P. T. Penny and J. V. S. Pether (5 February, p. 375) refer to vaccination against rubella in high-risk non-pregnant workers such as nurses. For the past four years there has been a staff occupational health department at Bedford Hospital. Routine blood examination is done to assess the haemagglutination-inhibition antibodies (H.A.I.) of female staff and where there is an H.A.I. titre less than 64 rubella immunization is offered. Our results bear out those of Drs. Penny and Pether.

\begin{tabular}{l|r|r}
\hline & 1970 & 1971 \\
\hline Total tested & 170 & 135 \\
Susceptible & 37 & 28 \\
Immune & 133 & 107 \\
\hline
\end{tabular}

I also confirm the unreliability of a history of rubella. Our figures are that in 1971 out of a total of 135 tested, there was a definite history of rubella of 43 , rwo of whom were susceptible and 41 immune. Those with no history of rubella were 92 , out of whom 25 were susceptible and 67 immune.-I am, etc.

JOHN D. HARTE

Staff Occupational Health Bedford

\section{Payment by Colour}

SIR,-In 1969, you highlighted the pay discrimination of doctors' salaries in South Africa, and in a leading article entitled "Payment by Colour" (7 June 1969, p. 586) reminded us that "this inequity is of concern to doctors beyond the boundaries of South Africa."

I have recently returned from King Edward VIII Hospital, Durban, where I was the last and at that time only white house phvsician in that vast black hospital. Mine was one of the rare remaining opportunities left in South Africa for a white to 